\title{
Activism in the Fast Lane: Social Movements and the Neglect of Time
}

\author{
Kamilla Pietrzyk
}

\begin{abstract}
If we continue to follow the acceleration of human technological time so that we end in the black hole of oblivion, the earth and its bacteria will only smile at us as a passing evolutionary folly.
\end{abstract}

Over the past decade, research on the so-called anti-globalization movement - better termed the global justice movement (GJM)1 - and on other aspects of transnational organizing, has grown substantially. Much of the recent thinking on the GJM emphasizes the role played by transnational information and communication technologies (ICTs), in particular the Internet, in providing what is seen as an unprecedented opportunity to build a virtual network of global citizens. According to these commentators, thanks to the new ICTs, social movements appear to be acquiring the organizational and strategic capabilities that may turn them into genuinely powerful political actors (e.g. Dartnell 2006; Meikle 2002; Rheingold 2002). As Nick Dyer-Witheford (1999) argues convincingly in CyberMarx, the Internet has permitted previously dispersed and isolated points of resistance to 'rhizomatically' connect and combine with each other.

While it is important to acknowledge the instrumental value of ICTs for progressive social actors, the intention of this paper is to problematize the prevailing celebratory approach by drawing attention to the central role played by communication media in facilitating what Marx called "the annihilation of space by time," and the associated cultural neglect of time. More specifically, my key concern is that the pervasive spatio-temporal imbalance fosters a mode of social consciousness that is short-term, unreflexive and ahistorical, in turn shaping the strategic propensities of political activists in advanced, "fast capitalist" societies in significant and potentially deleterious ways.

The article is organized in three parts. First, I outline the article's theoretical framework, which combines an approach to communication studies known as medium theory with the basic dynamics of capitalism as laid out in Marxian thought. The aim of this interdisciplinary framework is to facilitate a complex, historical understanding of how, in the broader context of capitalism, instantaneous media of communication shape the ways in which people conceptualize and organize social relations in space and time. The second part examines how capitalism's systemic imperative to accelerate the turnover time of capital penetrates (largely hidden) temporal norms, and how it is ironically and revealingly reflected in the predominant forms of activist mobilization, which tend to increasingly privilege speed and spatial reach to the detriment of duration. Finally, the brief conclusion offers some tentative suggestions for moving beyond this short-term, myopic impasse.

\section{Medium Theory}

According to Ron Deibert (1997), medium theory is an approach crafted to show how historical change emerges as a result of shifting relations involving media of communication. Medium theorists examine the structural features of various media when trying to understand how each medium differs from others in terms of its political-economic, 
psychological and sociological implications. A key facet of medium theory is the belief that "media are not simply neutral channels for conveying information between two or more environments, but are rather environments in and of themselves" (Deibert 1999: 273). Raymond Williams (1973), albeit not a medium theorist, described the influence of the material conditions of any system with the expression "the setting of limits and exertion of pressures" (1973:4). This expression captures admirably well the dialectical relationship between a medium of communication and the character, cognition and cultural capacity of the society in which it operates.

Furthermore, as Babe (2000) and Comor (2001) have argued, medium theory does not limit the definition of communication media to speech, writing, telegraph, telephones, radio, and so forth. From a medium theory perspective, institutions, technologies and organizations all constitute media broadly defined insofar as they serve as "key nodal points through which social knowledge is produced and reproduced" and which accordingly affect people's thoughts and behavior (Comor 2001:276). Modes of transportation, both natural ones such as rivers or lakes and human-made ones such as canals, roads, and railways, constitute communication media as do schools, churches, and markets, and money (Babe 2000:59). In maintaining a broad definition of a "medium," medium theory asserts that, "[t]hough related to technology, a medium is not simply a technology, but the social relations within which a technology develops and which are rearranged around it. A medium is thus a mode of social organization, defined not by its output or production but by the relations obtaining within it" (Angus 1998:17).

Unlike most content-based approaches to communication, medium theory is also necessarily historical, contrasting different media environments across time, and tracing changes in communication media for their effects on the evolution of social and political order (Deibert 1999:21). According to Robert D'Amico, historicism can be defined as a thesis of "how human understanding is always a 'captive' of its historical situation" (cited in Cox 1996:281). In contrast an "essentialist" mode of thought, medium theory views history "not in terms of unchanging substances but rather as a continuing creation of new forms" (ibid). From this dynamic perspective, rationalities, systems, and states - though potentially stable in their basic characteristics over long periods of time - are nonetheless the products of historical contingencies and are thus subject to change as societies evolve (Deibert 1997:278).

\section{| Harold Innis and "The Bias of Communication"}

One scholar whose own approach to medium theory is particularly relevant for our purposes is Harold Innis, a Canadian economic historian turned communication scholar. After he abandoned his initial training as an economist to pursue communication research, Innis set out to investigate the role played by media of communication in shaping the dynamics of large-scale social and political change. He was particularly interested in the influence of communication media in relation to how different civilizations apprehend and organize themselves in terms of time and space - the two fundamental indices of the human experience. Innis turned to communication studies precisely because he wanted to trace the evolution of temporal and spatial conceptualizations across civilizations, and because he believed that "communication technology, far more obviously than other forms of technology, directly intervenes in the structuring of time-space relations" (Watson 2006:327-28).

Innis believed that most civilizations tend to have a cultural orientation towards either space or time - an orientation closely connected to the communication media available to that society. In order to trace this connection across civilizations, Innis developed the concept of media "bias," arguably the most significant heuristic device found in his later writings. Innis first used this concept to enable social scientists to become more explicitly reflexive in their work. He maintained that while objectivity is impossible, social scientists can develop tools to become aware of their own subjectivities, to understand how they are constructed and how and why they are unconsciously expressed. The question posed by one of Innis's undergraduate philosophy professors, Ten Broeke, "why do we attend to the things to which we attend?", informed Innis's formulation of bias; indeed, it should be understood as the defining question in Innis' communication studies (Comor 2001:275).

In analyzing Innis's communication research, Robert Babe (2004) explains how, given their structural capacities, media tend to privilege, or be biased towards, either time or space. Media that are relatively easy to use and transport and that have an abundant capacity to store information but are not durable (e.g., paper) were considered by Innis to be space-biased. They give rise to, and support, space-biased cultures, which Innis characterized as "secular, present-minded, and intent on territorial expansion and administration of vast territories" (Babe 2004:384). These technologies "allow the acquisition, transmission, and control of information over an ever-expanding geographical 
space" (ibid). Paper, for instance, lent itself to the creation and administration of the Roman empire - its lightness enabled an army of officials to coordinate their activities over vast expanses of space, simultaneously reducing the amount of time for decision-making. Because technologies such as paper "are light, easily reproduced and disseminated, and quickly replaced, they facilitate the control of space, but do not further...the preservation of knowledge for perpetuity" (Berland 1999:285). By contrast, media that are relatively intractable (e.g. stone carvings), difficult to transport, durable, and that are limited in their capacity to store information were deemed by Innis to be time-biased because they support and induce time-biased cultures, characterized as "ceremonial, communitarian, hierarchical, in tune with custom and tradition, religious and geographically confined” (Babe 2004:384).

At this point it is important to note that while the concept of media "bias" shaping societies may bring to mind technological determinism (and some have accused Innis of just that), Innis conceptualized "bias" in "decidedly non-deterministic ways" (Cox 1995: 8; original emphasis). This is because the structural characteristics of a medium that make it prone to privilege either space or time are never comprehensible outside the social-economic context of their use (Comor 1994:112). The development and use of a new means of communication into a specific society will shape, and be shaped in turn, by the political economic conditions existing in that society at the time. As such, from a medium theory perspective, one cannot evaluate the impact of new technologies, including new media, without also examining the material foundations of society involving its means of production, distribution and consumption, and the structured relationships related to them. No medium operates in a vacuum; media work in a relationship of dialectical influence with a society's particular political-economic configuration. These conditions continue to modify how a medium functions even as they themselves undergo transformation due how people use the medium in question (Comor 2001). Furthermore, Deibert argues that the charge of technological determinism leveled against Innis signals a common misreading of his work because "bias," properly understood, constitutes a heuristic device:

$[S]$ pace/time biases are better conceived of as shorthand designates for the supports and constraints presented by different communication media for prevailing mentalities and institutions throughout history... [T]o say that Sumerians were time-biased is not to reduce it to the medium of communication; it is to reveal the way the material context and available technologies of the time constrained or supported existing institutions, social groups and mentalities. (Deibert 1999:286)

Deibert's words highlight the fact that Innis's main goal in The Bias of Communication (1951) was not to cast media as direct determinants of the course of history. Instead, Innis endeavoured to use media as focal points through which macro-historical developments can be better understood in relation to the micro-level of conceptual systems, or modes of consciousness (Cox 1995:8).

\section{Media and Consciousness}

In pursuing communication studies, Innis placed such a heavy emphasis on the categories of time and space because he believed that these constitute "the fundamental conceptions in the make up of human consciousness" (Watson 2006:327). Similarly, Cox (1995) argues that the distinction between the space and time bias in Innis goes beyond "institutional configurations" - it relates even more to orientations of the human mind. Innovation in communication technologies "affect not only the physical relations among people and the centralization or decentralization of authority but also, and perhaps most importantly, the structure of consciousness" (Carey 1975:35). The relevance of Innisian medium theory to this study's assessment of the global justice movement directly involves its focus on "how the historically specific techniques of communication set channels in which perception runs and how, therefore, the thought of the times is related to the structures of the channels of perception" (Watson 2006:296).

For Innis, "reality" is neither God-given nor simply a product of what we observe. How human beings conceptualize themselves, their world and their interests is shaped by various media which influence, and are in turn influenced by, prevailing political-economic relations. Innisian medium theory emphasizes the role played by media in shaping conceptual systems - what human beings use in the task of processing information and experience into what is known. In short, medium theory is characterized by an analytical sensitivity to "the perspective imposed by the technique of communication" (Watson 2006:364).

Conceptual systems can be defined as interrelated, interworking sets of values, ideas, and beliefs that shape every individual's worldview; they serve to filter or sift through the vast amounts of information people receive from 
their external environment and through direct experience. Media of communication constitute a significant element in the process of socialization through which these conceptual systems are formed. Referring to Innis's writings, James Carey points out that "knowledge is not simply information...There is no such thing as information about the world devoid of conceptual systems that create and define the world in the act of discovering it" (1975:45). For Innis, the ability to define what reality is constitutes the fundamental form of social power because human actions are controlled and constrained according to ways in which their realities are defined (ibid:44).

In the final years of his life, Innis became preoccupied with the pervasive lack of interest in problems of duration - what he called the "obsession with present-mindedness" of Western civilization (Innis 1951:76). "Each civilization has its own methods of suicide," Innis warned (1982:141). To his mind, culture ought to be primarily concerned with "the capacity of the individual to appraise problems in terms of space and time and with enabling him to take the proper steps at the right time" (Innis 1951:85-86). Contemporary western civilization, Innis thought, was teetering on the brink of self-annihilation because it was losing its general ability to redress its cultural imbalances.

In concentrating his studies on the ways in which different civilizations have organized and conceptualized time and space, Innis perceived that modern Western history started with a time-biased tendency and moved toward being dangerously space-biased. Referring to Innis's ideas, Ian Angus writes: “[O]ur society has been extremely efficient in media oriented towards space. We have more and more organization over a larger and larger area... What we do not do well is organize things in the dimension of time" (1998:24). In his essay "A Plea for Time," Innis called for a correction to this imbalance. As an antidote to the contemporary and pervasive space bias, he promoted the oral tradition, which he held to be a key component in creative and critical thought, as exemplified by the ancient Greek culture, whose popular use of "mnemo-technique" served as a means of building up and transmitting their cultural heritage over centuries (Watson 2006:372). Yet rather than pushing for a dominance of time-biased relations and conceptual systems, Innis saw the tension or balance between time-biased and space-biased media as the ideal. As Innis (1951) put it:

A stable society is dependent on an appreciation of a proper balance between the concepts of space and time. We are concerned over control not only over vast areas of space but also over vast stretches of time. We must appraise civilization in relation to its territory and in relation to its duration. The character of the medium of communication tends to create a bias in civilization favourable to an over-emphasis on the time concept or on the space concept and only at rare intervals are these biases offset by the influence of another medium and stability achieved. (P. 64)

For Innis, "The oral tradition was both fecund and sterile in a fashion exactly contrary to the written tradition... [1] thad the ability to disseminate ideas but was obliged to depend on oral sources for creativity in thought" (Watson 2006:353). Its disintegration in modern society was, for Innis, accelerated by mechanical mass communication - the reading of books, newspapers and magazines, listening to radio, watching films (Innis 1995:47). The process of systematizing and amplifying the reproduction of contemporary (mostly commercial) sources of information - what Innis called "the mechanization of knowledge" - involves significant implications for intellectual and cultural capacities insofar as it fosters a "dispossession of time and the resources of memory" and renders marginal "nonrational" forms of knowledge, including history, myth, and the oral tradition (Berland 1999:305). "The quantitative pressure of modern knowledge," Innis wrote, "has been responsible for the decay of oral dialectic and conversation" (1995:351). As information started to be transmitted at speeds too great for people to process with care, for Innis, it was "growing too vast for successful use in social judgment" (ibid). At the same time, orally transmitted knowledge important for cultural balance and potential efflorescence - was increasingly pushed to the periphery of the human experience through the predominance of space-biased communications. The "mechanization of knowledge" thus was serving to diminish cultural conditions needed to facilitate creative thought by tilting the balance between space and time in favor of space.

Combined with the structural conditions of capitalism as delineated in the Marxist tradition, the Innisian approach allows for an understanding of the deep-seated changes in our consciousness effected by any given predominant configuration of space and time relations --changes that shape social movement activists" "imagination" and strategy. Like Marxism, medium theory examines historical changes at the macro-level but it also examines the role of media in shaping ways of thinking and acting. For Innis, the historical struggles of groups or classes to gain power have usually entailed the effort to control the temporal and spatial conditions of life. In this respect, Innis's analysis of media as forces shaping ideological production and the classes which sustained and were sustained by them "constitutes the core of a materialist interpretation of the relations between the economic base of a society and its superstructure which complements Marx’s analysis” (Parker 1977:560). Parker continues: 
A full incorporation of Innis' analysis into contemporary Marxist thought would require a recognition that the "forces of production" of any historical political-economic system comprehend not only the population, the means of material production, and the resource base, but also the communications media or networks which sustain and are sustained by that system: the forces of ideological reproduction, and the transport media which are conditioned by and determine the structure of spatial-temporal relations between individuals and classes within the system. (ibid)

While Innis was not directly influenced by Marx's work, Parker demonstrates that their writings are complementary in several important aspects. Before examining the ways in which predominant media shape the strategic propensities of today's political activists, medium theory directs us to first assess with more depth the capitalist dynamics, forces and processes dialectically structuring these media of communication.

\section{The Capitalist Speed Imperative}

To reiterate, the temporal and spatial characteristics of society can only be properly understood by situating them in the larger context of the political economy in question. In the context of the modern world order, capitalism expands because it is has to; it is a system organized around competition and competitive market relations, which, for Marxists, are organized around the dynamic to extract more surplus value from labor and to subsequently realize this value (as profits) through sales. This basic dynamic, known as the labor theory of value, informs the competitive relations among capitalists.

According to Barbara Adam (1995), the contemporary industrial way of work is fundamentally dependent on clock time. In her discussion of the time economy of work relations, Adam explains that "surplus value and profit cannot be established without reference to time" (89) since "to be profitable means to spend as little money as possible on labor time" and "[t]o be competitive is to be faster than your rival" (100). This is why the values of efficiency, profitability and competitiveness have all been highly valorized in advanced capitalist societies, giving rise to the contemporary "speed fetishism" (101). The precise calculation of time in connection with these values, says Adam, forms the core of the process that Marx theorized as the commodification of time. While she emphasizes that life in industrialized Western societies is not dominated exclusively by the time of the clock - which continues to coexist with the complex, variable and open-ended times of the body and natural cycles - Adam rightly stresses the hegemonic status of commodified, decontextualized, quantifiable and empty time, which has served capitalism for centuries in its role as a standardized unit of exchange.

Echoing the argument that competition and the profit motive constitute the underlying rationales for the contemporary imperative toward speed, David Harvey has identified two incessant drives in the capitalist system: the drive "towards the reduction if not elimination of spatial barriers, coupled with equally incessant impulses towards acceleration in the turnover of capital" (2000:98). In the words of Marx, commenting on the capitalist impulse to revolutionize the means of transportation (themselves media of communication, broadly defined), capital must "strive to tear down every spatial barrier to...exchange, and conquer the whole earth for its market" and "annihilate this space with time, to turn over capital in the "twinkling of an eye"' (Marx 1973:538-9). Marx could already see that the spread of railways, telegraph and steam navigation would tend to accelerate the means of communication and transport, leading to periodic bouts of "annihilation of space by time" (Rosenberg 2005:21-22). Capitalism loves speed because, as Benjamin Franklin observed over two hundred years ago, time is money.

Harvey (1990) argues moreover that, historically, the emergence of recent, digitally-based ICTs constituted one of the ways in which capitalism responded to the collapse of Fordism in the mid-1970s. Capitalism required greater flexibility with respect to labor processes and markets, products, and patterns of consumption. The shift to the postFordist "regime of flexible accumulation" was partially achieved through the rapid deployment of new organizational forms and new technologies of production that brought to the fore entirely new sectors of production, new ways of providing financial services, new markets, and above all, "greatly intensified rates of commercial, technological, and organizational innovation" (Harvey 1990:147). These and other organizational shifts constitutive of postFordist restructuring benefited enormously from the development and implementation of new ICTs, which enabled capitalists to improve efficiencies and extend their control of various markets across geographical space. Harvey (1990) explains the significance of instant communication in what he calls the process of "time-space compression":

Accurate and up-to-date information is now a very highly valued commodity. Access to, and control over, information, 
coupled with a strong capacity for instant data analysis, have become essential to the centralized co-ordination of far-flung corporate interests. The capacity for instantaneous response to changes in exchange rates, fashions and tastes, and moves by competitors is more essential to corporate survival than it ever was. (P. 159)

Instantaneous ICTs have also played a crucial role of the post-Fordist regime of flexible accumulation by facilitating the transnationalization of finance, with informational facilities now in place for the continuous and real-time flow of monetary information, the round-the-clock trading in stocks, bonds, and currencies, which bounce from exchange to exchange in response to slight shifts in the market, frequently without human input as computers handle the transactions automatically for traders (Webster 1995:143; Deibert 1997: 153). It also allows corporations to maximize competitive advantage by arranging, for instance, to locate headquarters in New York City, design facilities in Virginia, and manufacture in the Fast East, with sales campaigns co-ordinated from a London office. Referred to by some scholars as the new international division of labour, this orchestration of globalized production and marketing strategies by transnational corporations would have been impossible without instantaneous media like the Internet. Furthermore, by using ICTs to obtain "time leads" over competitors, corporations can obtain potential "extra-profits" before the competition catches up. For instance, the ability to "beat the competition" in accessing the latest trend, product, or scientific discovery implies the possibility of an important competitive advantage and thus constitutes a vital aspect of successful profit-making (Harvey 1990:159).[2]

\section{The Neglect of Time}

Capitalist dynamics, particularly the imperative to increase control over space and reduce capital turnover time, have been structured into dominant media of communication, broadly defined. I contend that through these media, the conceptual systems and practices of more people in more parts of the world are becoming increasingly preoccupied with immediate or relatively short-term concerns. In the context of capitalism, the accumulated result of these spatially biased structures is deepening a spatio-temporal cultural imbalance, which Innis saw as detrimental to people's creative resources and intellectual capacities.

Historically, as it became easier to communicate more quickly over large geographic spaces (thanks to the printing press, followed by the telegraph and the telephone), the temporal norms of society underwent profound modifications. The speed of life, defined as "the number of an individual's episodes of action and/or experience per units of time" generally accelerated (Rosa 2006:448). With "time efficiency" structured into and, in turn, promoted by spatially biased technologies, organizations, and institutions, people's responses had to become more immediate in response to emerging norms of timeliness. Notions such as "saving time," having no time, running out of time, or being "up with the times" gained greater currency in an increasingly time-conscious culture (Lubrano 1997:120). Simultaneously, the relatively "slow" oral tradition that Innis championed as a counterweight to the spatially biased Western society, was increasingly marginalized. As Berland (1999) argues, because of their structural predisposition toward the rapid dissemination of large amounts of information across vast territories, predominant media serve to marginalize or altogether obliterate those media "appropriate to memory, tradition, spirituality, and dialogue - all aspects of oral culture that have been appropriated and transformed through the production of technological space" (292). Like media before it, the Internet, dubbed by Todd Gitlin (2001:76) as "the latest speed demon" works to obliterate time as it is being structured to serve the interests of "fast capitalism" (Agger 1989; 2004). In this light, the Internet can be understood as what Innis would refer to as a spatially biased medium.

Of course, the Internet is not the sole, all-powerful mediator of contemporary conceptual systems, culture, and economic order. Today's preeminent media, broadly defined, also include the American state and its ongoing efforts to control or expand the boundaries of US interests specifically, and capitalism more generally. Capitalist consumption similarly exerts a powerful influence by promoting the desire for instant gratification and individualistic self-fulfillment through commodities.

Recognizing the presence of other powerful media, however, need not divert us from assessing the Internet's biases. In the context of the "developed" world in the early twenty-first century - the so-called "age of information" - the Internet plays a key role in deepening the prevailing preoccupation with spatial expansion, organization and control through shrinking time frames. While communication media, once established and widely accessible, can be used in ways unintended by those who initially created and structured them, the most prominent providers of Internet services and content continue to be dominated by profit-seeking interests. These interests also have the 
greatest input in determining the national and international policies that shape the medium's development. In this broader context, the Internet continues to perpetuate the existing tendency to prioritize spatial reach and speed over duration.

One important manifestation of this tendency is the astounding ephemerality of information disseminated on the Web. The Internet can reach virtually anywhere in the world, provided sufficient infrastructure and the availability of telephony; therefore, all its information potentially has a global reach.3 But the ability to transmit and receive information from almost any part of the world instantaneously has been accompanied by a growing neglect of duration: as Innis recognized, to the extent that a medium excels at controlling space, it is generally less efficient at controlling time. Thus, while the Internet's infrastructure itself is robust, the messages transmitted online are highly perishable and are easily obliterated with the push of a button (Frost 2003). According to web archivist Brewster Kahle, the World Wide Web has a "memory" of about two months (cited in Brand 1999:48). Materials published on the Web that derive from professional sources, such as libraries or databases, have their analogs elsewhere; this ensures that they will still be available even after they vanish from digital view. Other kinds of digital documents, however, tend to disappear within days (Deegan and Tanner 2002).

As with other structural properties of the Internet, the ephemerality of web content should be understood in the context of the systemic imperative toward an acceleration of production, distribution and consumption. The technologies used to archive digital data face high rates of obsolescence because most companies have little economic incentive to develop lasting data storage solutions. Faced with the pressures of fast capitalism, information technology companies have to perpetually innovate their products - and the upgrades themselves, of course, are supposed to make computers and the capitalist system that relies on them run faster and more efficiently, contributing to the general speedup.

For Simons (2006), the fact that as technology for writing becomes more advanced, the products of writing generally become less durable represents "one of the great ironies of our age." Echoing Innis, he points out that clay and stone used thousands of years ago to record important information lasted thousands of years, and that the parchment used hundreds of years ago lasted hundreds of years. Even acid-free paper has proven to last for centuries. Today, digital technologies, including both hardware and software, are changing so rapidly that a typical storage medium or file format is obsolete within five to ten years. Indeed, given the accelerating rates of obsolescence and ephemerality of the Internet and related technologies, "there has never been a time of such drastic and irretrievable information loss as right now" (Simons 2006).

The absence of archives in a context of growing amounts of obsolete data suggests that we are now living in a period that may prove "a maddening blank" to future historians - a digital Dark Age - because almost all of our art, science, news and other records no longer have lasting, physical analogs, being directly created and stored on media "that we know can't outlast even our own lifetimes" (Brand 2003:48). The obsolescence of digital data, especially on the Web, both reflects and perpetuates a cultural tendency toward the neglect of duration. Because it provides a way to constantly update information, the Internet is perpetually rendering obsolete the information we already have, exacerbating the problem of impermanence and "obsessive present-mindedness" that Innis associated with modern media. As Brand warns, the "price of staying perfectly current is the loss of cultural memory" (2003:38).

\section{History and Memory}

The loss of this type of memory can already be observed among activists, many of whom appear to largely lack awareness of the history of social justice struggles. Having (online) access to texts documenting these struggles is of course requisite for gaining this awareness, which is why the ephemerality of online texts is so disturbing; however, mere access is not enough in a cultural milieu wherein historical thought itself has been marginalized. While further empirical research is necessary, preliminary anecdotal and case study evidence (Pietrzyk 2007) allows me to feel justified in positing that given what is perhaps an unprecedented emphasis on the present and immediacy, there seems to be no observable incentive or interest to learn the lessons of the past to inform contemporary strategy and vision-building. In such a scenario, the potential for creativity and innovation in social activism becomes reduced, for it is arguably more difficult to build a new social order when one has little idea about what has already been tried and its results.

The question of memory is an important one when assessing the capabilities and potentials of contemporary 
activists. According to social movement scholars, cultural and institutional memory are significant aspects of successful activist organizing (Della Porta and Diani 1999:184-85). However, to the extent that the predominant media in contemporary Western society are conducive to speed and spatial control, they make it relatively difficult to hold onto a sense of historical continuity. The extraordinary ephemerality of Internet-mediated information offers one example of the neglect of long-term thinking prevalent in our culture.

In her commentary on the difficulties afflicting volunteerism, Ellis (2003) is weary of the lack of institutional memory in volunteer-driven organizations, including contemporary social movements. The need for institutional memory in such groups is particularly pronounced, she argues, because of the high rates of turnover in leadership positions: "New ways of doing things seem to spring up without any consciousness of what happened in the past (...) newcomers often initiate change simply because of their own preferences or the wish to establish a 'new administration.' Many fail to ask an important question first: Why and how did we end up where we are now?” (original emphasis). While she acknowledges the importance of avoiding getting bogged in past failures, she insists that "we are all too busy to reinvent the square wheel or duplicate the hard efforts of predecessors. The key is to do some research before we set off in a new direction" (Ellis 2003).

Likewise, global justice activists Cobarrubias and Casas (2007) identify an "unhealthy lack of trying to reflect on what has been done (actions, campaigns, movements, and so forth), learn lessons, share those lessons and tools with others, and in a more long-term way recuperate genealogies of movements' struggles." Echoing Ellis's concern with the neglect of institutional memory, they observe:

\begin{abstract}
Activists do not know how to learn from their history - how to keep it alive - or even how to produce and share or own history with others..... Often, even simple things like keeping track of a collective's activities, being able to share its history with others, are left by the wayside in the grind of daily activist work or organizing response actions. Groups that are fighting against the same exact targets don't know what people three or four years ago did, what worked and what didn't.... [I]t's a question of a lack of historical memory - not only of what movements did 100 or 70 years ago but of what they did 10 and 20 years ago. (Cobarrubias and Casas 2007)
\end{abstract}

The lack of cultural and institutional memory identified above is magnified through the Internet and other spatially biased media. The Internet represents a communicative environment wherein users are encouraged to "click onto the next thing" and where website designers work under the basic premise that they have mere seconds to grab the viewers' attention before they surf away to find something more interesting (Frost 2003). In this respect, the Internet shapes the very mode of thought in modern society by affecting attention spans and memory. In reference to Innis in Watson (2006) argues that space-biased media such as the Internet convey great amounts of information quickly and promote a perception of time that is much more "cut-up" and "short-term" when compared to previous generations (419).

Some would argue that the generations growing up in the contemporary "developed" world have "evolved" to handle the informational onslaught by developing superior skills at "multitasking." However, there exists some evidence to suggest that the overload of information facilitated by the Internet and other ICTs entails deleterious consequences not only for cultural and institutional memory, but also for human organic (biological) memory. For instance, a study done in Tokyo in 2001 has linked severe memory loss experienced by increasing numbers of young people to a growing dependence on computer technology. A preliminary examination of one hundred people between the age of twenty and thirty-five revealed that serious problems with their memory afflict more than one in ten, with those afflicted reporting an inability to recall names, written words or appointments. The severity of their memory problem has even forced some to leave their jobs. The researchers argue that devices like electronic organizers "lead to diminished use of the brain to work out problems and inflict 'information overload' that makes it difficult to distinguish between important and unimportant facts." "It's a type of brain dysfunction," said Toshiyuki Sawaguchi, the university's professor of neurobiology. "Young people today are becoming stupid" (Norton 2001:A1).4

If we take note that for Innis, culture is primarily concerned with "the capacity of the individual to appraise problems in terms of space and time and with enabling him (or her) to take the proper steps at the right time" (Innis 1951:85-86), we begin to get a better idea of memory's importance in resolving collective, long-term problems. As Heather Menzies argues in her book No Time, memory is crucial to critical thinking "in both its aspects: the broad range of personal experience, chance observations and overheard chat, plus the deeper wells of accumulated and composted knowledge, wise nuggets and one-liners against which we test new information, sensing contradictions and resisting accepting the latest idea or news flash simply because it is new" (2005:186).

Given their structural propensities toward spatial reach and speed, the Internet and other ICTs are not conducive 
to facilitating this kind of accumulated, "composted knowledge." For David Solway, the problem is that young people today suffer from "aphasia," or "an inability to articulate themselves as social and historical subjects." He has coined his own term, "chronosectomy," which he describes as "a kind of lobotomy in that part of the brain that senses time as personal and shared continuity" (Menzies 2005:188). He worries that contemporary youth do not perceive themselves as "being part of, even immersed or embedded in, a continuum of time, and as a result they seem to be simultaneously moving at the speed of light and going nowhere" (ibid:189). Solway's concern is shared by Rosa, who maintains that social acceleration "counteracts our capacity to relate episodes of experience to a sense of identity, history and the communities we are part of. Episodes of experience thus remain just that: episodes that pass without a trace, without being transformed into lived experience" (2005:458).

\section{Information Overload}

In exploring the influence of the Internet and other space-biased, instantaneous media on the creative resources and intellectual capacities of political actors, we also need to examine the problem of information overload. Innis (1951) believed that improvements in communication tend to make understanding more difficult. The mechanical amplification of the amount of available information was initiated on a large-scale with the advent of printing and perpetuated with each wave of technological innovation. With the advent of instantaneous, global systems of communication it has reached new heights. More information is available to an individual with access to these technologies than ever before; however, such a vast increase of available information is not necessarily "good news." As Innis realized, innovations in systems of communication do not necessarily lead to greater knowledge. On the contrary, the general trend in innovation, leading to ever "lighter" and ephemeral communications (highly efficient over distances but of short duration), help foster a culture that is rich in information, but poor in analysis, particularly when the commercial dynamic (and its emphasis on sensual titillation) is involved.

According to Surman and Reilly (2003), information overload is one of the biggest problems of networked activism. Mads Hassar (2001) observed that "We are less patient, less willing to take the time, perhaps because we have less of it since there is so much we feel we need to digest in order to keep up" (cited in Hassan 2003:139). This problem represents a substantial challenge to "networked" social movement organizations: as they continue to produce more and more information, it becomes difficult for activists to know where to start - "or possibly more importantly, where to stop" (49). There is simply too much information to absorb. One cause of this problem is the emphasis of data collection over analysis - our culture excels at producing and disseminating large volumes of information but runs aground when it comes to synthesizing it. As Naomi Klein writes: "We are producing more and more data - statistics, case studies, best practices. However, we often see this information thrown out to the world in a fairly raw form with no analysis or even explanation of the framework in which the information can be understood" (Klein 2000:51). In the context of capitalist ICTs, fast information usually wins. What gets lost along the way? For Eriksen (2001:70), "the short answer to this question is context and understanding" while Hassan (2003:137) observes that the increasing immersion in the real-time, chronoscopic temporality of the network means that we are left with no time to develop knowledge, expertise and critical thought, without which we cannot live through consciousness in the past nor project possible futures.

\section{Dominance of the Visual}

The loss of memory and the strong possibility that our capacity to filter "important" information, from a torrent of trivia is diminishing, are not the only potentially disturbing element in relation to the creative and intellectual capacities of contemporary social movements. These capabilities are being further undermined by the visual orientation of predominant media, including the Internet. Our space-biased civilization privileges sight, or visual knowledge, as a dominant mode of communication - something that deeply disturbed Innis.

In his admiration for the cultural heritage of orally-based societies, Innis developed a critique of "the dominance and isolation of the visual in the dominant era" (Watson 2006:347). He maintained that as a result of the dominance of the visual, “"perception' becomes replaced with sensation' as the central function in human consciousness" and that "sensory imbalance and political instability" represented "two sides of the same phenomenon" (ibid). In a 
similar vein, Frost (2003) argues that "visual media promote specific, limited modes of perception and understanding and of economic and spatial organization, which shape the society and culture in which they circulate." Visual media are conducive to inducing feeling, not critical, reflexive thinking. Such knowledge is usually practical or entertaining , yet it tends to reduce our ability to critically reflect upon what we are seeing.

For Innis, "biases tend to be cumulative and self-reinforcing" (Comor 2001:283). The conceptual systems of people living in the 21 st century are being shaped by the aggregate effects of long-standing spatially biased, fastpaced media; from the telegraph to radio, from television to the Internet. In particular, the visual and space and time-annihilating tendencies of television are being intensified with the growing use of Internet medium.5 To make the argument that the Internet is a predominantly visual medium is not to ignore the continuing presence of text online, including websites and discussion boards. Rather, it is to call attention to the fact that biases, whether those of space or time, or the privileging of sight, influence each other. The introduction of a new medium, especially by relatively marginal social forces seeking to challenge existing power centers, may well serve to undermine the bias of other, preexisting media and help to bring about a new social order. However, if the development and the application of these new media is structured by biased vested interests and conceptual systems, these media generally will take on already dominant biases. Given capitalism's systemic tendency to maintain and extend the torrent of images that stimulates our senses and the "modern" desire to consume, the Internet generally reflects and deepens the visual orientation of preexisting, predominant media.

Even a quick Internet journey using one's Internet browser will reveal the dominant positioning of images on the Web. Text found on the Internet also has been affected by the privileging of the visual. Students of Internet "usability" learn that the average Internet user spends mere seconds in evaluating the attractiveness of a website; to entice the user to stay, any text must be short, broken up into short paragraphs, and surrounded by lots of "white space." Above all, to attract the "reader" (or more to the point, the website "viewer"), textual information typically is surrounded by colorful, appealing images, diagrams, and illustrations. It would thus appear that if people are choosing to spend their time on the Internet rather than watching television (see Putnam 1999:179), it is likely because the Internet can "outperform" television by offering content that is more engaging, sensually titillating, and "controllable" with just a click of a mouse.6

Since we are all more or less used to the hyper tempo of spatially and visually biased, predominant media, it can be difficult to find evidence of their influence on conceptual systems. In this respect, it is useful to examine cultural relics. For example, one of the most striking aspects of films made in the fifties, at least from our contemporary perspective, is how sluggish they are, with slowly unfolding dialogues and lingering scenes (Eriksen 2001:85). Todd Gitlin likewise observes that while looking back over the past fifty years of Western cultural production, "it is hard to resist the impression that the movies were slower, newspaper and magazine articles longer, sequences longer and more complex, advertising text drawn out." In comparing the images and dialogue in films from the 1920s through the 1950s, he remarks how "strikingly slow" they seem. In these early films, the camera typically remained still and the scene stayed put; today, the restlessness of the camera is matched by the relentless montage of clips (Gitlin 2001:88-9).

Examining cultural relics like old movies can be illuminating in their ability to reveal the extent to which our conceptual systems have been shaped by cultural speed up. Yet such an examination is fairly narrow in its focus. From an Innisian perspective, it is no substitute for developing a mode of thinking that strives to continually reflect upon its own unconscious biases.

\section{| The Need for Reflexivity}

It is difficult to deny that in the rushing capitalist world, most people not only have to think fast, they also have to act fast. I have been arguing that this speed imperative can be observed not only in relation to the systemic pressures of fast capitalism and the decisions made by political leaders, but also in dominant forms of activist engagement. With individualistic and immediate gratification common sense characterizing modes of consciousness, many forms of activist organizing appear to be prioritizing speed and spatial reach over sustainability. Forms of engagement become more and more oriented toward short-term, instrumental mobilizations that may inspire, but often fall short of the sustained, "committed" action needed to effect substantive change. Long-term strategybuilding is typically eschewed, as the dominant pattern among the current generation of activists (at least in advanced 
capitalist countries) seems to enthusiastically embrace the cause du jour (determined in most cases by a volatile commercial news agenda) and spend some time vigorously organizing a "day of action": a demonstration, a festival, or a film screening. Once the action is done, participants tend to feel a little better about themselves and, more often than not, subsequently turn to a new and different social justice issue, choosing from the plethora of more or less titillating causes available in what one commentator calls "the theme park of radical action" (Blühdorn 2001). Not without bitterness, "one time deal" is how a friend once characterized this self-gratifying, strategically myopic style of engagement. Many "networked" activists "temporary, ad hoc organizations entail less commitment than the more laborious task of nurturing sustained alliances and erecting stable political organizations. The capitalist imperative toward speed is thus ironically and revealingly reflected in the prevailing emphasis on taking action in the here and now, often with no time or energy to debrief afterwards or more generally, consider the usefulness of action taken for the sake of action (Featherstone et al 2004).

In observing the new generations of Western activists, Canadian cultural critic Hal Niedzviecki has became convinced that when they try to raise awareness of their particular cause, "the line between chronicling dissent and using one's status as a protester to enter the pop world and further an "I'm-Special agenda is a thin one" (2004:218). This general sentiment was well captured by one young activist, who proclaimed enthusiastically that "Going to Québec City was, without a doubt, the craziest, most dangerous, most fun experience I've ever had” (ibid).7 To be sure, this is not to say that activism cannot or should not be fun. Yet based on the present analysis using medium theory and also my own experiences with activism in Canada, Niedzviecki's point rings distressingly true when he asks: "How many of the mostly middle-class Westerners who protested at the antiglobalization rallies of the early millennial period were in attendance at least as much to be there as to "work for change?" (ibid:218; original emphasis). Much heartfelt idealism and real effort undoubtedly factors into the work of activist youth; however, anecdotal and first-hand experience suggests that, frequently, this tends to be the case for a considerable number of activists, for whom superficial political engagement serves as a vehicle to "reinvent themselves and affirm their specialness" (Niedzviecki 2004:221). Against the background of a "me-first," short-term outlook common to many activists, "[p]seudo-rebellion blurs into passivity. We start to think that seeing a film or videotaping a protest is the same thing as actually striking a blow against the evil corporation, tantamount to rejecting the latest ultra-convenient polluting apparatus in favor of some benevolent alternative" (ibid:223).

This self-absorbed, instant gratification mode of activism manifesting itself in "summit-hopping," with its promise of colorful marches, cultural performances, extreme thrills should the authorities decide to intervene, and above all, its ability to make one feel special and "radical," might best be understood in the context of a spacebiased culture, mediated by technologies such as the Internet. Such media facilitate an acceleration in the pace of life while reducing the general capacities needed to critically assess the ways in which we go about "doing" radical politics. By enabling an accelerated mode of interaction, ICTs promote what Robert Hassan (2003:142-143) calls "abbreviated thinking" and the associated foreshortening of political imagination. In applying this line of critique to social movements, Featherstone et al (2004) have deployed the term "activistism" to describe what they perceive as the prevalent pragmatist emphasis on action "for its own sake" that fails to reflect upon its own impotence.

From an Innisian perspective, one corrective to this myopic style of engagement is through the development of a mode of thinking that strives to continually reflect upon its own unconscious biases. Reflexive thinking refers to the ability of groups and individuals to appreciate the biases that impact their thinking and which are enacted unconsciously time and over again. For Innis, the importance of reflexivity stemmed from his belief that "the search for knowledge is not the search for final truths, for the Known, but for an understanding of the limitations of knowledge. This is the only real knowledge" (Watson 2006:296).

The task of developing a reflexive mode of thought is not easy, for it is virtually impossible to obtain an objective perspective in relation to one's own self, yet it is not too unfeasible to discover one's own limitations. Innis maintained that the "sediment of experience" provides the basis for this investigation. While it is difficult if not impossible to predict one's own course of action, it can be done with respect to the course of action of other people. To uncover one's own biases, therefore, one can observe the predictable habits or biases of others (Innis 1995:433). In relation to social movements, activists may learn to become more self-reflexive by observing the biases played out in the process of planning and executing a protest or other activities.

If they succeed at gaining a degree of self-reflexivity, activists can then bring it to bear not only upon how they choose to pursue their objectives, but also to reflect upon the objectives themselves. Innis observed that the social scientist who succeeded at becoming more self-reflexive in terms of their biases can take comfort that "thought in the social sciences grows by the development and correction of bias. On the other hand, he [sic] will receive small 
thanks and possibly much contempt and persecution for attempting to tear the mask from innumerable biases which surround him" (Innis 1995:432). In recommending reflexivity for social movement actors, the question thus arises whether it is salutary for activists to adopt this intellectual strategy: to refuse to accept "final truth" and relentlessly question their motives and activities. Insofar as strong and unshakable faith in one's ideals is advantageous in the formidable effort to change the world, such an approach conceivably could undermine the strength of one's convictions. There is thus a tension at work here: on the one hand, self-reflexivity can undermine whatever confidence activists bring to their work. On the other, reflexive capacities are needed to recognize and possibly counteract the biases that are potentially influencing goals and strategies in deleterious ways.

While recognizing this tension, I venture that self-reflexivity takes precedence over self-assurance. Reflexive thought needs to be at the forefront of contemporary activism if activists are to develop the kind of intellectual and creative capacities necessary to correctly identify and analyze the deeply rooted systemic problems of capitalism as well as their own biases.

\section{| Final Remarks}

By way of concluding, I wish to emphasize that I recognize the instrumental value of instant, digital communication media, including the Internet, for social movement activists. Through email, message boards, file transfers, and so forth, movement activists across the globe can now coordinate a transnational campaign or orchestrate a protest within weeks, sometimes even days, without ever physically gathering in one place. As exemplified by "Global Days of Action" and other large-scale protests, Internet-mediated networks have proven very effective at uniting large groups of people in very short periods of time. In my own work as a member of various Canadian movements, I too have relied extensively on the Internet and other media as tools of organization and mobilization. And yet, as I have argued in this article, given that the speed with which worldwide movement mobilization can now take place is, in fact, historically unprecedented on account of new media of communication like the Internet, activists appear to be increasingly putting speed and spatial reach above organizational sustainability, reflecting the short-term, ahistorical, and immediate gratification common sense perpetuated by contemporary capitalist media.

Finally, I do not mean to suggest that in order to recognize and rectify the pervasive myopic outlook of spacebiased cultures, activists should permanently turn off their computers and television sets, and devote their free time to solitary meditation. I am calling, however, for more reflexive thought within activist practice. As this paper has suggested, the Internet might perhaps be better understood not as a revolutionary tool or solution, but as part of the problem confronting today's social actors. As Agger suggests, "[s]lowing down is easier said that done" (2004:131). Nonetheless, future successes of contemporary social movements may well depend on the ability of activists to recognize the way in which fast media such as the Internet are influencing their political self-expression, and to rethink and re-evaluate their uses of such media. To offer one example, rather than investing their energies into yet another spectacular though short-lived and largely ineffective "global Day of Action," movement activists could use the Internet to begin the process of becoming acquainted with the rich theoretical and historical legacy of past antistatus quo struggles. Additional strategies likely can be devised for the paradoxical deployment of space-biased media to counter our speed-obsessed culture and modes of thinking and acting. Ultimately, whether they use the Internet or not, the greatest challenge confronting the new generations of activists will involve efforts to build some places and spaces where ordinary people can become empowered to think critically and collectively about the better world we wish to create.

\section{Endnotes}

1. The term "anti-globalization" is regarded by the movement's participants as unduly negative and is typically eschewed in activist discourse in favour of more positive monikers, such as "alter-globalization", "globalization from below" or the "global justice movement" (GJM).

2. It is important to note that such dynamics, of course, are not new; they have long generated the annihilation of space and time and can be explicated in terms of 
ongoing, if accelerating, trends. What has changed is that instantaneous communication systems are now instrumental in facilitating this competitive advantage on a global scale.

3. Of course, as Frost (2003) and others have pointed out, the digital divide remains a serious obstacle to Internet connectivity around the world, and that in many places even basic telephony is not available.

4. Other scholars and medical professionals also are starting to recognize the problem. Professor Pam Briggs, who chaired a British Psychological Society symposium on the effects of technology, said: "I think increased use of the Internet and computer technology is starting to have an effect. Everyday memory might be at threat if you are using the computer as a kind of external memory." Likewise, David Cantor, director of the Psychological Services Institute in Atlanta, Georgia, argues that, "information overload is making it difficult for some people to absorb new information as they have reached a limit of what they can store in their brains. These people forget things because they were too distracted to absorb them in the first place" (cited in Norton, 2007: A1).

5. With the advent of television, Western civilization's short-term, unreflexive and ahistorical outlook reached new heights, since moving images constitute a relatively more "potent" form of communication insofar as they appeal to human beings at a relatively visceral and sensual level than do print or radio, emphasizing the emotional over the rational (Gitlin 2001). Television's propensity to promote immediacy, individualism and sensation to the neglect of thought and duration is related to its role as a purveyor of a consumerist outlook. Through consumption, immediate gratification and individualist satisfactions have been promoted to the extent that shortterm, "me-first" orientations now play a significant role in the common sense of most Western cultures (Comor 2003: 9). Sut Jhally (1991) points to the shrinking time span of television commercials as advertisers' response to the growing "clutter" of the commercial environment and the coming of age of a generation raised on fastpaced video games and television programming. Jhally is worried that the speed of television advertising "has replaced narrative and rational response with images and emotional response. Speed and fragmentation are not particularly conducive to thinking. They induce feeling" (84). The neglect of time perpetuated by television can also be observed with respect to televised news programmes. A typical news broadcast consists of decontextualized "sound-bites," sewn together to the visual accompaniment of rapidly flashing images. Neil Postman (1985) concluded that "we are by now so thoroughly adjusted to the 'Now..this' world of news - a world of fragments, where events stand alone, stripped of any connection to the past, or to the future, or to other events - that all assumptions of coherence have vanished" (110).

6. Gitlin (2001) believes that there is pleasure in the ability to speed through a torrent of images on screen while remaining physically still. It is a different sort of pleasure of the kind Mark Crispin Miller (1990) calls "subvisual" - "visceral pleasure at the disorientation that results from a sequence of bursts, pleasure at immersion in a wild procession of fragments, the sort of pleasure that, extrapolated from moving pictures to the other arts, has come to be called 'postmodern.' The montage is the message, and the message is that the torrent feels good" (94). In a sense, the Internet functions like "TV on steroids," reflecting and deepening television's predominant biases. Concentration and contemplation, two qualities of "slow" thought being undermined by fast media, become an even greater anachronism in the online environment, "where everything is fast and facile" (Menzies 2005: 7).

7. The documentary produced by the Toronto Video Activist Collective about the protests during the Québec City Summit of the Americas is revealingly titled Tear Gas Holiday (“Tear Gas”).

My sincere thanks extend to Dr. Edward Comor for his peerless intellectual guidance. I would also like to thank the Social Sciences and Humanities Research Council of Canada for financial support.

\section{References}

Adam, Barbara. 1995. Timewatch: A Social Analysis of Time. Cambridge: Polity Press.

-----. 2002. "The Gendered Time Politics of Globalization: Of Shadowlands and Elusive Justice." Feminist Review 70:3-29.

Agger, Ben. 1989. Fast Capitalism. Urbana, Illinois: University of Illinois Press.

----. 2004. Speeding Up Fast Capitalism: Cultures, Jobs, Families, Schools, Bodies. Boulder, CO: Paradigm Publishers.
Angus, Ian. 1998. “The Materiality of Expression: Harold Innis' Communication Theory and the Discursive Turn in the Human Sciences." The Canadian Journal of Communication 23:9-29. Babe, Robert. 2000. Canadian Communication Thought: Ten Foundational Writers. Toronto: University of Toronto Press.

---. 2004. "Innis, Environment and New Media." Pp. 383-412 in Seeking Convergence in Policy and Practice: Communications in the Public Interest, Vol. 2., edited by M. Moll and L. Regan Shade. Ottawa: Canadian Center for Policy Alternatives. 
Berland, Jody. 1999. "Space at the Margins: Critical Theory and Colonial Space after Innis." Pp. 281-308 in Harold Innis in The New Century: Reflections and Refractions, edited by C. R. Ackland and W. J. Buxton. Montreal: McGill and Queens University Press.

Blühdorn, Ingolfur. 2006. "Self-Experience in the Theme of Radical Action? Social Movements and Political Articulation in the Late-Modern Condition." European Journal of Social Theory $9(1): 23-42$.

Carey, James. W. 1975. "Canadian Communication Theory: Extensions and Interpretations of Harold Innis." Pp. 27-59 In Studies in Canadian Communication, edited by G. Robinson and D. Theall. Montreal: McGill University.

Cobarrubias, Sebastian and Maribel Casas. 2007. On the Road: the US Social Forum. Infoshop News. Retrieved November 2009 (http://www.infoshop.org/inews/article. php?story $=20070613102922644)$.

Comor, Edward. 1994. "Harold Innis's Dialectical Triad.” Journal of Canadian Studies 29(2):111-127.

-.---. 2001a. "Harold Innis and the Bias of Communication." Information, Communication and Society 4(2):274-294.

-.---. 2001b. "The Role of Communication in Global Civil Society: Forces, Processes, Prospects." International Studies Quarterly 45:389-408.

-----. 2003. "Neo-Imperialism and the Crisis of Time." Topia 10:1-22.

Cox, Robert.W. 1995. "Civilizations: Encounters and Transformations.” Studies in Political Economy 47:7-31.

Dartnell, Michael. Y. 2006. Insurgency Online: Web Activism and Global Conflict. Toronto: University of Toronto Press.

Deegan, Marilyn and Simon Tanner. 2002. “The Digital Dark Ages." Library + Information Update 1(2), May 2002:42-43.

Deibert, Ronald. J. 1997. Parchment, Printing and Hypermedia: Communication in World Order Transformation. New York: Columbia University Press.

-----. 1999. "Harold Innis and the Empire of Speed." Review of International Studies 25:273-289.

Della Porta, Donatella and Mario Diani. 1999. Social Movements: An Introduction. Malden, MA: Blackwell.

Dyer-Witheford, N. 1999. Chicago: University of Illinois Press.

Ellis, Susan. J. 2003. "The Need for Institutional Memory." Energize Inc. Retrieved June 11, 2007 (http://www.energizeinc. com/hot/2003/03dec.html).

Eriksen, Thomas Hylland. 2001. Tyranny of the Moment: Fast and Slow Time in the Information Age. London, Sterling, VA: Pluto Press.
Featherstone, Liza, Doug Henwood, and Christian Parenti. 2004. "Action Will Be Taken: Left Anti-Intellectualism and Its Discontents." Lip Magazine, November 11. Retrieved November 25, 2009 (http://www.lipmagazine.org/articles/ featfeatherstone_activistism.shtml).

Frost, Catherine. 2003. "How Prometheus is Bound: Applying the Innis Method of Communications Analysis to the Internet." Canadian Journal of Communication 28(1):9-24.

Giddens, Anthony. 1990. The Consequences of Modernity. Stanford, CA: Stanford University Press.

-----. 2001. Media Unlimited: How the Torrent of Images and Sounds Overwhelms Our Lives. New York: Metropolitan Books.

Gleick, James. 1999. Faster: The Acceleration of Just About Everything. New York: Vintage Books.

Harvey, David. 1990. The Condition of Postmodernity: An Enquiry into the Origins of Cultural Change. Oxford: Blackwell.

-----. 2000. The New Imperialism. Oxford: Oxford University Press.

Hassan, Robert. 2003. The Chronoscopic Society: Globalization, Time and Knowledge in the Network Economy. New York: Peter Lang.

Heilbroner, R. L. 1980. Marxism: For and Against. New York: W. W. Norton and Co.

Innis, Harold A. 1950. Empire and Communication. Toronto: University of Toronto Press.

-----. 1951. The Bias of Communication. Toronto: University of Toronto Press.

-----. 1995a. “The Mechanization of Knowledge." Pp. 350-356 in Staples, Markets, and Cultural Change: Selected Essays of Harold A. Innis, edited by D. Drache. Montreal: McGillQueen's University Press.

-----. 1995b. "The Penetrative Powers of the Price System on New World States." Pp. 66-88 in Staples, Markets, and Cultural Change: Selected Essays of Harold A. Innis, edited by D. Drache. Montreal: McGill-Queen's University Press.

-.---. 1995c. "The Role of the Social Scientist." Pp. 429-38 in Staples, Markets, and Cultural Change: Selected Essay of Harold A. Innis, edited by D. Drache. Montreal : McGillQueen's University Press.

Jhally, Sut. 1991. "Image-Based Culture: Advertising and Popular Culture." Pp. 77-87 in Gender, Race and Class in the Mass Media: A Text Reader, edited by G. Gines and J. Humez. London: Sage Publications.

Klein, Naomi. 2002. Fences and Windows: Dispatches from the Front Lines of the Globalization Debate, edited by D.A. Levt. Toronto: Vintage Canada. 
Lubrano, Theresa A. 1997. The Telegraph: How Technology Innovation Caused Social Change. New York and London: Garland Publishing.

Marx, Karl. 1973. The Grundrisse. Penguin: Harmondsworth.

Meikle, Graham. 2002. Future Active: Media Activism and the Internet. London: Routledge.

Menzies, Heather. 2005. No Time: Stress and the Crisis of Modern Life. Vancouver, BC: Douglas and McIntyre.

Nabokov, Peter. 2002. A Forest of Time: American Indian Ways of History. Cambridge University Press.

Nesbitt-Larking, Paul. 2001. Politics, Society and the Media: Canadian Perspectives. Peterborough, Ont: Broadview Press.

Niedzviecki, Hal. 2004. Hello, I'm Special: How Individuality Became the New Conformity. Toronto: Penguin Canada.

Norton, Craig. 2001. "Computer Generation Suffers a Memory Crash: Young People 'Becoming Stupid' Because of Reliance on Technology: Scientist." The Ottawa Citizen, February 4, p. A1.

Postman, Neil. 1985. Amusing Ourselves to Death: Public Discourse in the Age of Show Business. New York: Penguin.

Pietrzyk, Kamilla. 2007. "Exit from the Myopic Impasse: Social Movement Strategy in the Age of the Internet." M.A. thesis, The Faculty of Information and Media Studies, The University of Western Ontario, London, ON.

Rheingold, Howard. 2002. Smart Mobs: The Next Social Revolution. Cambridge, MA: Basic Books.

Rosa, Harmut. 2005. "The Speed of Global Flows and the Pace of Democratic Politics." New Political Science 27(4):445-459.
Rosenberg, Justin. 2005. "Globalization Theory: A Post Mortem." International Politics 42:2-74.

Simons, Gary. F. and SIL International. 2004. "Ensuring that Digital Data Last: The Priority of Archival Form Over Working Form and Presentation Form." An expanded version of a paper originally presented at the EMELD Symposium on Endangered Data versus Enduring Practice. Linguistic Society of America annual meeting, January 8-11, 2004, Boston, MA. Retrieved June 14, 2007 (http://www.sil.org/ silewp/2006/003/SILEWP2006-003.htm\#1).

Surman, Mark and Katherine Reilly. 2003. "Appropriating the Internet for Social Change: Towards the Strategic Use of Networked Technologies by Transnational Civil Society Organizations." Social

Science Research Council. Retrieved June 23, 2007 (http://mediaresearchhub.ssrc.org/appropriatingthe-internet-for-social-change-towards-the-strategic-use-of-networked-technologies-by-transnationalcivil-society-organizations/ resource_view).

Toronto Video Activist Collective. "Tear Gas Holiday." Retrieved December 22, 2009 (http:// greatworm.ca/catalog/video. html).

Watson, James A. 2006. Marginal Man: The Dark Vision of Harold Innis. Toronto: University of Toronto Press.

Webster, Frank. 1995. Theories of the Information Society. London, New York: Routledge.

Williams, Raymond. 1977. "Base and Superstructure in Marxist Cultural Theory.” New Left Review 1(82):3-16. 
